\title{
Letter from the editor for the first issue of JTSP
}

\author{
J. Gruenwald' \\ ${ }^{1}$ Gruenwald Laboratories, Taxberg 50, 5660 Taxenbach, Austria
}

(Received: 05. July 2018, Accepted: 05. July 2018, Published online: 05. July 2018)

DOI: $10.31281 /$ jtsp.v1i1.2

editor@jtsp.eu

Dear friends and colleagues,

it is my privilege and pleasure to write this letter and to introduce the new online, open access Journal of Technological and Space Plasmas (JTSP). The first article is scheduled to appear on the $15^{\text {th }}$ of July 2018 and I am looking forward to more high quality articles to come over the course of the following months and years. The main goal of JTSP is to offer plasma scientists and technologists a fresh platform for sharing their ideas online to a wide range of people around the globe. The journal will not only be promoted throughout the scientific community but also along the industrial network of its publisher, G-Labs. JTSP'S coverage is focussed but not limited to the following fields of plasma physics, encompassing pure, applied, theoretical and experimental research, as well as interdisciplinary topics:

- Technologically relevant plasmas

- Plasma medicine

- Fusion Science and Technology

- Plasmas for Space Applications

- Space Plasmas (i.e. Physics of the magnetosphere, of stars, etc.)

The manuscript types can be full articles, letters or review papers, which will all go through a thorough yet fast peer review process (usually not more than two weeks to three weeks). The motivation for issuing this new journal is the idea that science should be accessible by everyone and that open access should not be hampered by large cost for the authors. Thus, JTSP has special offers for first time authors and a reward system for dedicated referees. I am confident that this will encourage also young scientists to become a part of the JTSP network and help spreading science across the globe. I strongly believe that getting scientific results of high quality out to the public is now more needed than ever. Therefore, I am looking forward to receive your contributions and please check out our journal website www.jtsp.eu for further details.

Sincerely,

Dr. Johannes Gruenwald

Editor-in-chief

(c) (i)

Open Access. This article is licensed under a Creative Commons Attribution 4.0 International License, which permits use, sharing, adaptation, distribution and reproduction in any medium or format, as long as you give appropriate credit to the original author(s) and the source, provide a link to the Creative Commons license, and indicate if changes were made. The images or other third party material in this article are included in the article $s$ Creative Commons license, unless indicated otherwise in a credit line to the material. If material is not included in the article's Creative Commons license and your intended use is not permitted by statutory regulation or exceeds the permitted use, you will need to obtain permission directly from the copyright holder. To view a copy of this license, visit: http://creativecommons.org/licenses/by/4.0/. 